\title{
Nutritional Neuroscience as Mainstream of Psychiatry: The Evidence- Based Treatment Guidelines for Using Omega-3 Fatty Acids as a New Treatment for Psychiatric Disorders in Children and Adolescents
}

\author{
Jane Pei-Chen Chang ${ }^{1,2,3}$, Kuan-Pin Su Su, $^{1,2,4}$ \\ ${ }^{1}$ Mind-Body Interface Laboratory (MBI-Lab) and Department of Psychiatry, China Medical University Hospital, ${ }^{2}$ College of Medicine, China \\ Medical University, Taichung, Taiwan, ${ }^{3}$ Institute of Psychiatry, Psychology and Neuroscience, King's College London, London, UK, ${ }^{4}$ Department \\ of Psychiatry, An-Nan Hospital, China Medical University, Tainan, Taiwan
}

\begin{abstract}
Omega-3 polyunsaturated fatty acids (or omega-3 PUFAs, n-3 PUFAs) are essential nutrients throughout the life span. Recent studies have shown the importance of n-3 PUFAs supplementation during prenatal and perinatal period as a potential protective factor of neurodevelopmental disorders. N-3 PUFAs have been reported to be lower in youth with attention deficit hyperactivity disorder (ADHD), autism spectrum disorder (ASD) and major depressive disorder (MDD). N-3 PUFAs supplementation has shown potential effects in the improvement of clinical symptoms in youth with ADHD, ASD, and MDD, especially those with high inflammation or a low baseline n-3 index. Moreover, it has been suggested that n-3 PUFAs had positive effects on lethargy and hyperactivity symptoms in ASD. For clinical application, the following dosage and duration are recommended in youth according to available randomized controlled trials and systemic literature review: (1) ADHD: a combination of eicosapentaenoic acid (EPA) + docosahexaenoic acid (DHA) $\geq 750$ $\mathrm{mg} / \mathrm{d}$, and a higher dose of EPA $(1,200 \mathrm{mg} / \mathrm{d})$ for those with inflammation or allergic diseases for duration of 16-24 weeks; (2) MDD: a combination of a EPA + DHA of 1,000-2,000 mg/d, with EPA:DHA ratio of 2 to 1 , for $12-16$ weeks; (3) ASD: a combination of EPA + DHA of $1,300-1,500 \mathrm{mg} / \mathrm{d}$ for $16-24$ weeks as add-on therapy to target lethargy and hyperactivity symptoms. The current review also suggested that $\mathrm{n}-3$ index and inflammation may be potential treatment response markers for youth, especially in ADHD and MDD, receiving n-3 PUFA.
\end{abstract}

KEY WORDS: Attention deficit disorder with hyperactivity; Autism spectrum disorder; Inflammation; Major depressive disorder; Omega-3; Adolescent.

\section{INTRODUCTION}

More evidence showed that early interventions for neurodevelopmental disorders, such as attention deficit hyperactivity disorder (ADHD), autism spectrum disorder (ASD) and major depressive disorder (MDD), may help reduce the social economic burden of the patient, their family members and the society as a whole. Nutritional psychiatry has recently become a popular area of investigation due to the relatively low adverse effects profiles of the nutraceuticals and the accessibility of nutritional

Received: June 18, 2020 / Accepted: June 24, 2020

Address for correspondence: Kuan-Pin Su

Department of Psychiatry, China Medical University Hospital, No. 2, Yuh-Der Road, Taichung 404, Taiwan

E-mail: cobolsu@gmail.com

ORCID: https://orcid.org/0000-0002-4501-2502 products. Among the nutritional supplementations, omega-3 polyunsaturated fatty acids (or omega-3 PUFAs, n-3 PUFAs) have been suggested as a potential treatment for several neurodevelopmental disorders, especially those associated with inflammation-driven mechanisms; since n-3 PUFAs have been shown to ameliorate neuroinflammation with its anti-inflammatory and anti-oxidative properties. N-3 PUFAs are essential fatty acids (EFAs) for our mind and body throughout the life span. Recent studies have further shown the importance of n-3 PUFAs supplementation during prenatal and perinatal period as a potential protective factor of neurodevelopmental disorders. The association between n-3 PUFAs and ADHD, ASD and MDD will be reviewed in the aim to provide a preliminary clinical guideline for physicians for n-3 PUFAs supplementation for youth with these disorders.

@) This is an Open-Access article distributed under the terms of the Creative Commons Attribution Non-Commercial License (http://creativecommons.org/licenses/by-nc/4.0) which permits unrestricted non-commercial use, distribution, and reproduction in any medium, provided the original work is properly cited. 


\section{BRAIN, BEHAVIORS AND OMGEA-3 POLYUNSATURATED FATTY ACIDS (N-3 PUFAS)}

There are two main types of PUFAs in the human body, the omega-6 (n-6) PUFAs from the cis-linoleic acid (LA, $18: 2 n-6)$ and the $n-3$ PUFAs from the $\alpha$-linolenic acid (ALA, 18:3n-3). N-3 and n-6 PUFAs are important constituents of all cell membranes; they are called the EFAs, because they are crucial for the survival for the humans and mammals but cannot be synthesized within the body [1]; and can only be obtained from diets [1]. The PUFAs appear to be active in the biological function, and some of their functions require their conversion into metabolites including eicosanoids. Linoleic acid can be converted to gamma-linolenic acid (GLA, 18:3n-6) and GLA can be elongated to form dihomo-GLA (20:3n-6), which is the precursor of the prostaglandin (PG)-1s. Dihomo-GLA can also be converted to arachidonic acid (AA, 20:4n-6), which is the precursor of the PG-2s, thromboxanes (Txs) and the Leukotriene (LT)-4s. On the other hand, ALA can be converted to eicosapentaenoic acid (EPA, 20:5n-3) and EPA forms the precursor of PG-3s and LT-5s. In addition, EPA can be converted to docosahexaenoic acid (DHA, 22:6n-3). Both PGs and LTs are highly biologically active, have proinflammatory action and are known to be involved in the pathophysiology of inflammation-associated disorders, such as atherosclerosis, asthma, cardiovascular diseases, cerebrovascular diseases, inflammatory bowel syndrome, neurological diseases and metabolic syndrome [1-3].

Several lines of evidence support the importance of $n-3$ PUFAs in brain disorders [4-8]. DHA and EPA are both essential for the brain and the body, and the deficiency of both may impair brain development and attribute to the development of several brain disorders such as ADHD, ASD, dementia and depression. For example, DHA deficiency has been associated with neuronal membrane instability and dysfunctional transmission of serotonin, norepinephrine and dopamine [9], which might be associated with the mood and cognitive dysfunction of ADHD and depression. In addition, n-3 PUFAs helped to improve and prevent symptoms of depression [5,6,10,11], ADHD [7,12] and ASD [13], and cognitive function in mild cognitive impairment [8] in clinical trials.

\section{N-3 PUFAs and Neurodevelopment}

N-3 PUFAs deficiency especially in the early stages of life, may cause changes of myelination, neurogenesis, synaptogenesis, neurotransmitter turnover, brain connectivity, cellular differentiation and development, inflammatory reactions, cognitive functioning, and behavior. For example, deficiency of n-3 PUFAs in mothers during gestation have been associated with maternal depression and child neurodevelopment [14]. Animal models of maternal immune activation (MIA) with n-3 PUFAs deficient diet showed that these animal models have a higher central and peripheral inflammation than the MIA animal models with n-3 PUFA balanced diet, moreover, the offspring of the group with n-3 PUFAs deficient diet also had higher inflammatory interleukin (IL)-6 in the brain tissues, and a poorer spatial memory when compared with the offspring of those with n-3 PUFAs balanced diet [15]. Moreover, epidemiological studies showed that mothers who consumed little or no seafood, which contain n-3 PUFAs, have babies who have more suboptimal performance of neurodevelopmental measures [4].

N-3 PUFAs are incorporated into membrane phospholipids and the incorporation of DHA takes place in uniquely high levels in the brain [16]. DHA exerts several functions in process of neurogenesis, neurotransmission and protection against oxidative stress [17] and starts to accumulate in brain during pregnancy, especially in the second half of gestation [18], coinciding with the growth spurt in the grey matter [18]. Accumulation of DHA in the brain starts prenatally and continues up to two years after the birth of the baby [19]. Once high levels of DHA are achieved in the brain, they are maintained during later life, but this also depends on an optimal dietary supply, for example, the dominant source for DHA levels in adults are primarily from a diet with fish [20]. Moreover, the n-3 PUFAs modulate brain cell signaling via monoamine regulation, activation of signal transduction, and the modification of synaptic membrane and receptor properties via lipid rafts [21], which may explain their role in the onset of certain psychiatric diseases [7,8,22-24].

\section{N-3 PUFAs and Inflammation}

N-3 PUFAs have anti-inflammatory and immunomodulatory properties [23]; for example, n-3 PUFAs supple-

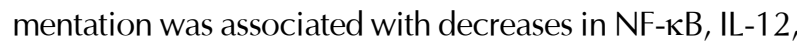
and IL-13 gene expression [25], and levels of macrophage 
inflammatory protein (MIP)-2, IL-6 [26], IL-17A [27], and tumor necrosis factor- $\alpha$ (TNF- $\alpha$ ) [28]. In addition, EPA is important in balancing the immune functions and physical health by reducing membrane AA (a n-6 PUFAs) and prostaglandin E2 (PGE2) synthesis [29], and which may be associated with medical comorbidity and somatic symptoms in depression [23]. Moreover, EPA and DHA have been shown to increase anti-inflammatory action via inhibition of free radical generation and oxidant stress [1]. Moreover, a recent animal study further showed that $\mathrm{n}-3$ PUFAs deficient diet exacerbated inflammation in an animal model of maternal immune activation, where the pregnant mice were injected with lipopolysaccharide to induce inflammation reaction, and induces spatial memory deficits in the adult offspring; while the offspring of the mice fed with n-3 PUFAs balanced diet during gestation had less central and peripheral inflammation and less memory deficits when compared with those of mice fed with n-3 PUFAs deficient diet [15].

\section{N-3 PUFAs and Gut-Brain Axis (GBA)}

Recently, researchers have suggested that the effects of n-3 PUFAs on the central nervous system, may be via the alteration of the GBA. GBA is the bidirectional communication system that allows gastrointestinal (GI) microbes to communicate with the brain [30]; it has been proposed that n-3 PUFAs may alter the gut microbiota and the microbiota produced short-chain fatty acids (SCFA), and transmit signals to affect brain function via the vagus nerve from the gut to the brain. Animal studies further supported that hypothesis by showing that a long-term administration of EPA/DHA in early-life-stressed rats led to the restoration of the normal Firmicutes/Bacteroidetes ratio and improved the stress-associated inflammatory conditions by increasing the abundance of butyrate-producing bacteria and decreasing the levels of pro-inflammatory bacterial genera, such as Akkermansia and Flexibacter $[31,32]$. Moreover, human study showed n-3 PUFAs supplementation increased neuroprotective Bifidobacterium and Lactobacillus in healthy volunteers and butyrate-producing (associated with anti-inflammation) bacterial genera [33], which may partially explain the anti-inflammatory mechanisms of n-3 PUFAs [33].

\section{CLINICAL CONDITIONS AND OMGEA-3 POLYUNSATURATED FATTY ACIDS}

\section{N-3 PUFAs and ADHD}

ADHD is a common neurodevelopmental disorder with a prevalence rate of $5-10 \%$ [34]. ADHD has a high comorbidity with other psychiatric disorders, including conduct disorders [35], mood disorders [36], anxiety disorders, and substance use disorders [37]; if left untreated, it will have a great impact on the society, including an increase in work absenteeism, school drop-outs, motor vehicle accidents, substance use problems and lower economic growth of the society as a whole [38]. Despite the good efficacy of the current pharmacotherapy children with ADHD- around $60-80 \%$, there are still about $20-$ $40 \%$ of patients with ADHD either respond poorly to the current medications available or suffer from medication side effects [39]. Thus, nutritional interventions such as n-3 PUFAs supplementation, also with its safety profile and anti-inflammatory effects, have been of great interest as a potential treatment for $\operatorname{ADHD}[7,12]$.

\section{Pre-clinical studies}

N-3 PUFAs deficiency has recently been investigated as a potential pathogenetic mechanism in $\operatorname{ADHD}[40,41]$. In epidemiological studies, children of mothers who have lower seafood intake during pregnancy are at risk of suboptimal outcomes for prosocial behaviours, fine motor coordination, verbal communication and social development [4]. Moreover, children with ADHD was shown to have a greater severity of EFAs deficiency, a clinical syndrome associated with insufficient fatty acid levels and comprising symptoms such as dry and scaly skin, eczema, and dry eyes [40]. In addition, Dietary EFA deficiency in children with ADHD correlates negatively with plasma DHA levels [41], while EFA deficiency presentation positively correlates with ADHD severity [40]. In terms of blood PUFAs levels, lower red blood cells PUFAs [41] and a higher $n-6 / n-3$ ratio [42] have been reported in ADHD, and lower n-3 PUFAs levels are positively associated with ADHD symptom severity in children $[42,43]$. A recent meta-analysis also showed that children with ADHD have lower blood levels of DHA, EPA and total n-3 PUFAs when compared with typically developing children [7].

Of note, single nucleotide polymorphisms (SNPs) of the 
fatty acid desaturase 1 (FADS1) and FADS2 genes, which code for the enzymes, delta- 5 desaturase and delta- 6 desaturase, responsible for the metabolism of polyunsaturated fatty acids, has been suggested to have significant association with ADHD [44]. ADHD has been associated with SNP rs498793 in the FADS2 gene, while the two SNPs rs174545 and rs174548 in the FADS1 gene were nominally associated with ADHD in the prenatal alcohol-exposed group of children [44].

\section{Clinical studies}

Although there were previous meta-analyses investigating the effects of n-3 PUFAs in ADHD [45-49], their findings might be confounded by heterogeneity in the clinical samples, including both children and adult subjects [47] or subjects with diagnosis other than ADHD $[45,48]$, as well as by the inclusion of non-parallel trials $[47,48]$, as well as mixed supplementation interventions including n-3 PUFAs together with vitamins and nutrients $[46,49]$. Thus, an updated meta-analysis, avoiding the limitations of the previous meta-analyses, showed that n-3 PUFAs have greater improvement in both inattention and total ADHD scores and cognitive function [7]. In addition, the subanalysis also showed that n-3 PUFAs supplementation with EPA > $500 \mathrm{mg} / \mathrm{d}$ improved clinical hyperactivity/ impulsivity symptoms [7]. Moreover, a previous study examining 10 ADHD clinical trials with 699 children with ADHD (predominantly males, $60-87 \%$ ) suggested that a high dose of EPA ( $1-2 \mathrm{~g}$ ) supplementation is required to show significant improvement of clinical symptoms in ADHD [50].

The findings from clinical trials of n-3 PUFAs in children with ADHD have been controversial. Some clinical trials with n-3 PUFAs supplementation in ADHD have shown improvement in clinical symptoms [51-53] and cognitive performances [54-56], but others have found no beneficial effects [57]. Moreover, most of the trials used DHA as the main component of the n-3 PUFAs $[53,54,56]$, or used a rather low combined dosage of DHA and EPA $(<500 \mathrm{mg} / \mathrm{d})[51,55]$. However, a recent study showed that high EPA dosage of 1,200 mg/d improved cognitive function (focused attention and vigilance) in those children with ADHD with a low EPA level (more inflamed), but did not improve cognitive function in those children with normal or high EPA level [12]. This further implies that subtyping ADHD with inflammation status or endogenous n-3 PUFAs level may contribute to the personalized medicine in ADHD with n-3 PUFAs as treatment; where endogenous n-3 PUFAs levels and inflammation status can be used as a treatment response predictor.

\section{N-3 PUFAs and ASD}

ASD is a complex neurodevelopmental disorder and its core symptoms are (1) deficits in social interaction, communication, and language. For example, they would have difficulty in establishing normal conversations, whether they involve verbal or nonverbal aspects and demonstrated social interest, emotion and affection and (2) repetitive and stereotypical behaviors and/or a restricted repertoire of interests such as insistence on doing the same things [58]. Children with ASD also frequently experience behaviour problems [13], immune- associated medical conditions and altered brain function [59].

Nutritional factors have been suggested to play a role in the development of ASD. Since there is the lack of effective medication for the ASD core symptoms, while some effective medications have multiple side effects, thus nutritional supplements, such as n-3 PUFAs, have been receiving much interest in improving ASD symptoms [13].

\section{Pre-clinical studies}

Both animal and human studies showed alterations in central and peripheral immune system functioning in ASD, such as the stimulation of immune cells, generation of autoantibodies, cytokine/chemokine imbalance, and increased permeability of the blood-brain barrier [60,61]. Children with ASD have higher plasma levels of PGE2, leukotriene and 8-isoprostane [62], and lower levels of antioxidant proteins. Moreover, increased levels of oxidative stress markers was associated with the ASD symptom severity [63]. These findings further support the speculation that there is a subpopulation in ASD that has immune system dysregulation that may contribute to the autistic phenotype, and by correction the immune dysregulation may help improve clinical symptoms.

Studies showed ASD have abnormalities in the gray and white matter of brain regions that are associated with social interaction, restrictive repetitive behavior, and sensory processing $[64,65]$ and an abnormal level of brain derived neurotrophic factor (BDNF, a protein that promotes the survival of neurons) which has been associated 
with severity of ASD symptoms [66]. On the other hand, n-3 PUFAs such as DHA have been reported to have positive effects on neurite survival, outgrowth and myelination in animal cultured cortical [67], sensory [68], and hippocampal neurons [69] by normalising BDNF and reducing oxidative damage [70]. In addition, n-3 PUFAs supplementation has been shown to decrease the gene expressions of NF-אB, IL-12 and IL-13 [25], MIP-2, IL-6 [26] and TNF- $\alpha$ [28].

The role of $n-3$ PUFAS in ASD could be explained by the enzyme defects involved in the conversion of $n-3$ PUFAs from their precursors or deficits in the process of incorporation of PUFAs into the cell membrane [71]. Genetic variants in FADS genes have been shown to enhance the conversion of AA from its precursors [72]. One FADS2 SNP and multiple FADS2 SNP (two SNP in males and nine SNP in females) have been associated with n-6 aggregate desaturase indices [72]. In addition, altered n-3 PUFAs metabolism has also been reported in APOE4 allele carriers [73]. The carriers, compared with non APOE4-carriers, have higher $\beta$-oxidisation rates of $n-3$ PUFAs [73]. Furthermore, altered messenger (mRNA) gene expression levels of fatty acid binding protein 7 (FABP7) were reported in post-mortem ASD brains, while increased hyperactivity and anxiety-related phenotype (two common features in ASD) in FABP7 knockout mice [74].

Epidemiological and cross-sectional studies showed that children with ASD, when compared with typically developing children, have lower levels of DHA, EPA, and higher total n-6 to n-3 PUFAs ratio [24]. Altered fatty acid composition in ASD has been suggested due to their restricted food preferences and limitation in n-3 PUFAs intake [75]. However, the intake of n-3 PUFAs in ASD remain controversial, where some reported a lower intake of ALA, the precursor of DHA and EPA [75], while others reported no difference in n-3 PUFAs intake [76]. Thus, this may further suggest that disturbed PUFAs metabolism rather than inadequate PUFAs intake may be the cause of altered fatty acid composition in ASD.

\section{Clinical studies}

On the other hand, open-label trials of n-3 PUFAs showed significant improvement in symptoms of ASD $[77,78]$. Despite this promising evidence, the findings from randomized controlled trials (RCT) investigating the effect of n-3 PUFAs on ASD symptoms remained incon- clusive. For example, one group showed that n-3 PUFAs $(\mathrm{EPA}+\mathrm{DHA})$ was superior over placebo in reducing stereotypy, inappropriate speech and hyperactivity [79], while another study failed to show any effect of n-3 PUFAs supplementation on autism severity symptoms, adaptive functioning, externalizing behaviour or verbal ability [80].

Thus, several meta-analyses attempted summarize the effect of $n-3$ PUFAs in ASD. A meta-analysis including 4 RCTs ( $n=107$ ) showed that $n-3$ PUFAs, compared with placebo, improved social interaction and repetitive and restricted interests and behaviours [24]. However, the findings cannot be generalised to all children with ASD because the included children predominantly comprised males, were of different age groups $(<8$ years-old to 28 years-old), displaying different symptom severity or high hyperactivity level. With regard to the potential effect of age, three out of six studies included a wide age range, which may have resulted in greater response variability. In addition, the trial duration also varied widely in studies included in this review $(6-26$ weeks). Since evidence suggested that it takes at least 6 months for PUFA to reach a steady state on the erythrocyte membrane [81] and at least 4 months to demonstrate an effect on cognitive performance [82], it has also been suggested that longer study periods up to one year might be needed to demonstrate n-3 PUFAs supplementation associated behavioural changes [83].

Another meta-analysis including 5 RCTs $(n=183)$ in children with ASD showed that n-3 PUFAs significantly improved lethargy symptoms of the Aberrant Behavior Checklist $(\mathrm{ABC})$ in the $\mathrm{n}-3$ PUFAs group compared with the placebo group, but a significant worsening of both externalizing behavior and social skills [84]. In addition, a recently published meta-analysis with updated studies (including 6 studies) in children with ASD suggests that supplementation of n-3 PUFAs may improve scores on the $A B C$ hyperactivity, $A B C$ lethargy, and $A B C$ stereotypy subscales $(n=109)$. However, no significant differences in clinical improvement as measurement of Clinical Global Impression-Improvement $(\mathrm{n}=169)$ or Social Responsiveness Scale total scores $(n=97)$. Most studies included in this meta-analysis used n-3 PUFAs dosages between 1.3 and $1.5 \mathrm{~g} / \mathrm{d}$ with duration of treatment ranging from 6 to 24 weeks; only one study used a much lower dosage of n-3 PUFAs (200 mg/d). Most participants were 
males and younger than 12 years and most trials excluded nonverbal participants or those with severe intellectual disabilities; therefore, the study results may only be applicable to small subgroups of ASD patients [13].

\section{N-3 PUFAs and MDD}

MDD is the leading cause of morbidity in youth, with a prevalence rate between $5-12 \%$ world-wide. However, there have only been a few evidence-based treatment options for pediatric patients, and only about $60 \%$ of pediatric MDD patients respond to treatment [85]. N-3 PUFAs deficiency has been reported in patients with MDD; moreover, patients with depression have also reported a lower level of n-3 PUFAs $[22,86]$.

\section{Pre-clinical studies}

Epidemiological studies observed that societies with high consumption of n-3 PUFAs have lower prevalence rates of depression [87], and clinical trials showed that n-3 PUFAs improved and prevented symptoms of depression $[5,6,10,11,88]$. Furthermore, n-3 PUFAs effectively treated depressive disorders in recent studies and some studies have shown EPA alone [89] or a combination of EPA and DHA $[10,88]$ had positive effects for patients with MDD. N-3 PUFAs improved the 4-month course of illness in patients with bipolar disorder in a preliminary trial [90], and in the further analysis and of the preliminary trial found that n-3 PUFAS are more beneficial in the depressive phase than in the manic phase in patients with bipolar I disorder [91,92]. In fact, n-3 PUFAs have been found to have antidepressant effects in several placebo-controlled trials [11].

The effect of n-3 PUFAs on MDD symptoms may also attribute to the alteration of gut-brain axis and the restoration of the autonomic nervous system (ANS) function via its effects on the heart rate variability (HRV). A growing body of literature suggested that a dysfunctional GBA may contribute to the pathophysiology of depression. Gut dysbiosis has been suggested to lead to depression-like behavior. Administration of antibiotics in mice was shown to lead to gut dysbiosis, depression-like behavior and altered neuronal hippocampal signaling, while such phenotype is reversible after administration of probiotic treatment with Lactobacillus casei [93]. Some studies further showed that by transplanting Gl microbiota from humans with depression to germ-free or microbiota-deficient rodents induces a depression-like phenotype, including anhedonia and anxiety-like behaviors [94,95]. However, such behavioral changes were not observed in mice receiving microbiota transplantation from healthy controls. Moreover, microbial produced SCFAs that were associated with alleviation of depression in mice [96], while depletion of SCFAs such as butyrate, acetate and propionate has been reported in MDD $[95,97]$. The fact the SCFAs dampen inflammation has suggest their antidepressant effects via anti-inflammatory properties [98]. However, their relations with inflammation still needs more clarification, since although butyrate has been shown to decrease neuroinflammation by action on microglial $G$ protein-coupled receptors 109a receptors [99], propionic acid has been shown to activate microglia in rats and promote immune cell recruitment in fatty acid receptor-3 mediated pathway [100].

Autonomic nervous system changes can also be found in altered mood states and appear to be a central biological substrate linking depression to a number of physical dysfunctions. ANS alterations result in vagal withdrawal, reflected by a decrease in HRV indices, and a decrease HRV has been associated with emotional dysregulation, and decreases in psychological flexibility and social engagement manifestations, which have been closely associated with prefrontal hypoactivity [101], one of the mechanisms contributing to the development of depression. Moreover, adolescents with depression or anxiety have lower HRV than controls [102], while those treated with antidepressants have been associated with a higher HRV [103]. In addition, n-3 PUFAs deficiency has also been associated with autonomic dysregulation [104]. On the other hand, n-3 PUFAs supplementation not only improve HRV, but also increase cellular n-3 PUFAs, and decrease risk for arrhythmias and sudden death [105]. Study also showed benefits of n-3 PUFAs supplementation in early life by increasing HRV $[106,107]$.

Moreover, it has been suggested that the genetic variations in phospholipase A2 and cyclooxygenase 2 genes, enzymes responsible for PUFAs metabolism, have been associated with the risk of inflammation- induced depression, possibly by lowering the levels of n-3 PUFAs such as EPA and DHA, which have anti-inflammatory properties, in both MDD patients [108] and medically ill patients treated with the pro-inflammatory cytokine interferon- $\alpha$ [109]. A recently published practice guideline for clinical use of 
n-3 PUFAs in MDD [110] suggested that n-3 PUFAs in MDD treatment should be considered for special populations including pregnant women [5,111-113], and children.

\section{Clinical studies}

There have been only a few studies using n-3 PUFAs monotherapy in pediatric depression, but with controversial findings [114-117]. A pilot study comparing the effects between n-3 and n-6 PUFAs in children and adolescents (age 7-18 years-old) with first time diagnosed depressive disorder (DD) and mixed anxiety and depressive disorder (MADD) for 12 weeks showed that n-3 PUFAs $(1,000 \mathrm{mg}$ EPA $+750 \mathrm{mg} \mathrm{DHA})$ is superior in the reduction of the overall depression symptoms. Moreover, the DD group showed greater improvement in depression symptoms than the MADD group [117]. Another study of $\mathrm{n}-3$ PUFAs in children with MDD $(\mathrm{n}=28$, age 6-12 years-old) for 16 weeks also showed that $n-3$ PUFAs (EPA $380-400 \mathrm{mg} / \mathrm{d}+\mathrm{DHA} 180-200 \mathrm{mg} / \mathrm{d}$ ) was superior to placebo in improving the MDD symptoms [116]. A third study of adolescents $(n=20)$ with treatment resistant MDD comparing high (16.2 g n-3 PUFAs: $10.8 \mathrm{~g}$ EPA + $5.4 \mathrm{~g}$ DHA) and low dosage (2.4 g n-3 PUFAs: 1.6 EPA + $0.8 \mathrm{~g}$ DHA) n-3 PUFAs showed that the high dosage group had $100 \%$ remission while low dosage group had $40 \%$ remission at the end of the 10 week-trial [114]. On the other hand, a study with medication-free adolescents ( $n=51$; aged 12-19 years) with DSM-IV-TR diagnoses of MDD were randomized to receive a fixed-flexible dose titration schedule based on clinical responses and side effects of n-3 PUFAs (EPA:DHA:2:1; with the initial dose of $1.2 \mathrm{~g} / \mathrm{d}$ was increased $0.6 \mathrm{~g} / \mathrm{d}$ every 2 weeks, up to a maximum of $3.6 \mathrm{~g} / \mathrm{d}$ [EPA $2.4 \mathrm{~g}+\mathrm{DHA} 1.2 \mathrm{~g}$ ]) or a placebo for 10 weeks did not show superior effects of n-3 PUFAs [116]. However, the authors suggested that the negative findings in their study may be due to not subtyping the patients at baseline for inflammation status.

\section{CLINICAL IMPLICATION AND PRACTICAL GUIDELINES}

\section{General Considerations}

N-3 PUFAs supplementation is important throughout of life span even during prenatal period, and n-3 PUFAs deficiency may contribute to the development of pediatric psychiatric disorders. Thus, adequate supplementation should be kept in mind for prevention and a higher dosage should be considered for specific disorders such as ADHD, ASD, and MDD in children and adolescents. The European Food Safety Authority has DHA dietary recommendations for infants and toddlers aged 6-24 months (100 mg DHA/d), however, they do not have specific recommendations for the adequate intake for children aged 2-18 years. Therefore, dietary advice should be consistent with the advice for the adult population, which should aim to achieve a mean daily intake of $250 \mathrm{mg}$ $\mathrm{DHA}+\mathrm{EPA}$. This can be achieved by consuming 1-2 fatty fish meal(s)/wk. When this is not possible, consuming supplements containing n-3 PUFAs is an option.

If children with ADHD, ASD and MDD want to take n-3 PUFAs, and are responding well with the current prescription of pharmacotherapy, they should continue with the current treatment and only consider use n-3 PUFAs as an augmentation to the current treatment. Moreover, they should always consult their healthcare provider before taking n-3 PUFAs supplements. Children manifesting with excessive thirst, frequent urination, skin bumps, and allergy may suggest that they have a greater severity in EFA deficiency [41], and n-3 PUFAs supplementation may be indicated to improve both their physical and mental well-being. Generally, the n-3 PUFAs dosage for ADHD, ASD and MDD falls between the range of $750 \mathrm{mg} / \mathrm{d}$ to 2,000 $\mathrm{mg} / \mathrm{d}$, where a combination of DHA and EPA is recommended $[7,12,13,114,116]$. The duration of $n-3$ PUFAs is usually recommended at 16 weeks, however, if the primary outcome include observable/measurable behaviour changes, the duration may extend up to 52 weeks [83]. Of note, lethargy, hyperactivity and stereotypy are specific symptoms in ASD reported to be responsive to n-3 PUFAs treatment [13] (Table 1).

\section{Safety Considerations}

Due to the relative safe and tolerability profile $[13,84]$ of n-3 PUFAs, they have been suggested as potential treatments for pediatric psychiatric disorders including ADHD, ASD and pediatric MDD. However, there are still come safety concerns regarding n-3 PUFAs. For example, it has been suggested that the potential antithrombotic effect of n-3 PUFAs may theoretically increase the risk for bleeding. However, according to Harris's systematic review on 19 available clinical trials with n-3 PUFAs sup- 
Table 1. Preliminary clinical guideline for children with ADHD, ASD, and MDD

\begin{tabular}{|c|c|c|c|}
\hline \multirow{2}{*}{ Categories } & \multicolumn{3}{|c|}{ Clinical conditions } \\
\hline & ADHD & ASD & MDD \\
\hline General & \multicolumn{3}{|c|}{$\begin{array}{l}\text { Should always consult the child's primary healthcare provider before initiation of any n-3 PUFAs supplementation } \\
\text { If the current medication showed good effect, the current medication should be continued in combination with n-3 PUFAS }\end{array}$} \\
\hline Dosage & $\begin{array}{l}750 \mathrm{mg} / \mathrm{d}(\mathrm{DHA}+\mathrm{EPA}) \text { in general; } \\
1,200 \mathrm{mg} / \mathrm{d} \text { (EPA) for those with high } \\
\text { inflammation or low n-3 PUFAs levels }\end{array}$ & $1,300-1,500 \mathrm{mg} / \mathrm{d}(\mathrm{DHA}+\mathrm{EPA})$ & $\begin{array}{l}\text { 6-12 years: } 1,000 \mathrm{mg} / \mathrm{d}(\mathrm{DHA}+\mathrm{EPA}, \\
\text { DHA:EPA: } 1: 2) ; \\
>12 \text { years: at least } 2,000 \mathrm{mg} / \mathrm{d}(\mathrm{DHA}+ \\
\text { EPA, DHA:EPA: } 1: 2)\end{array}$ \\
\hline Duration & $\begin{array}{l}16-24 \text { weeks: inattention } \\
52 \text { weeks: behaviour }\end{array}$ & $\begin{array}{l}16-24 \text { weeks: ABC lethargy, } \\
\text { hyperactivity and/or stereotypy }\end{array}$ & $12-16$ weeks: mood symptoms \\
\hline Safety & $\begin{array}{l}\text { Routine blood tests on fasting glucose, hem } \\
\text { months. } \\
\text { If clinicians are not familiar with high-qual } \\
\text { (RxOM3FAs). }\end{array}$ & $\begin{array}{l}\text { ogram and lipid profile (cholesterol, HDL, LI } \\
\text { lity n-3 PUFAs in the market, they should C }\end{array}$ & $\begin{array}{l}\mathrm{DL}, \mathrm{TG} \text { ) should be administered every } 6-12 \\
\text { onsider prescription } \mathrm{n}-3 \text { fatty acid products }\end{array}$ \\
\hline $\begin{array}{l}\text { Clinical } \\
\text { predictors }\end{array}$ & $\begin{array}{l}\text { Clinical symptoms such as excessive thirst, } \\
\text { may indicate a deficiency in EFAs such a }\end{array}$ & $\begin{array}{l}\text { frequent urination, dry hair, dry skin, dandr } \\
\text { S n-3 PUFAs. }\end{array}$ & uff, brittle nails and small bumps on the skin \\
\hline $\begin{array}{l}\text { Biomarker } \\
\text { predictors }\end{array}$ & $\begin{array}{l}\text { Low endogenous n-3 PUFAs levels } \\
\text { High inflammation such as elevated CRP }\end{array}$ & High inflammation such as elevated CRP & High inflammation such as elevated CRP \\
\hline
\end{tabular}

ADHD, attention deficit hyperactivity disorder; ASD, autism spectrum disorder; MDD, major depressive disorder; n-3, omega-3; PUFAs, polyunsaturated fatty acids; DHA, docosahexaenoic acid; EPA, eicosapentaenoic acid; ABC, Aberrant Behavior Checklist; HDL, high-density lipoprotein; LDL, low-density lipoprotein; TG, triglyceride; EFAs, essential fatty acids; CRP, C-reactive protein.

plementation for patients with high risk of bleeding $(\mathrm{n}=$ 4,397) [118], the risk for clinically significant bleeding is “virtually nonexistent!" Another potential safety concern is the susceptibility of n-3 fatty acid to undergo oxidation [119] , which may contribute to patient intolerance and potential toxicity $[120,121]$; however, the conclusions are highly inconsistent. Most of the published studies have shown either no change in oxidation [122-130], or a decrease in oxidation [131-141]. Other common reported side effects of n-3 PUFAs included gastrointestinal discomfort and irritability [24]. In addition, a recent meta-analysis involving 21 RCTs $(n=24,460)$ on the adverse effects of prescription $n-3$ fatty acid products (RxOME3FAs) showed that although there was no definite evidence of any RxOME3FA-emerging serious events, RxOME3FAs were associated with more treatment-related dysgeusia, skin abnormalities (eruption, itching, eczema), and mild adverse effects, and mild effects on non-lipid biochemistry measurements including fasting glucose, elevated alanine transaminase, elevated blood urea nitrogen, decreased hemoglobin and hematocrit [142]. Moreover, subanalysis showed that EPA/DHA combination were associated with more treatment related eructation and nausea and elevation of low-density lipoprotein cholesterol [142]. Thus, suggesting that even with the use of a relatively safe and tolerable treatment such as n-3 PUFAs, at least a 6- to 12-month periodic monitoring of biochemistry and lipid profile are recommended.

Another safety concern is the quality of the n-3 PUFAs. Since dietary supplements are different from prescription drugs and are usually loosely regulated, supplements do not have to meet strict government regulatory standards for purity, quality, efficacy and safety as pharmaceutical agents. As a result, fish oil dietary supplements in the market may contain certain concentrations of $n-3$ PUFAs and possibly saturated fatty or other containments [143,144]. On the other hand, prescription n-3 fatty acids (RxOME3FAs) may contain better quality n-3 PUFAs, since they have to follow the government regulations for pharmaceutical agents in the aspect of purity, quality, efficacy and safety.

\section{Future Direction}

In the future, where $\mathrm{n}=1$, personalized medicine is the step forward. Thus, biomarkers predicting n-3 PUFAs treatment response will be extremely important to provide patients with more effective treatment options. Studies have reported that those with a low endogenous n-3 PUFAs (or more inflamed) or a high inflammation status (perhaps elevated c-reactive protein, CRP, or increased inflammatory index) have been shown to respond better to n-3 PUFAs $[12,145]$. Moreover, stricter enrolment di- 
agnostic criteria will also affect n-3 PUFAs treatment efficacy. One meta-analysis showed that with patients with DSM diagnosis made by structured interview appear to be more responsive to $n-3$ PUFAs than those with self-reported psychiatric symptoms [146]. Thus, subtyping the individuals with ADHD, ASD and MDD with inflammatory status or endogenous n-3 PUFAs levels and clinical severity may help contribute to personalised medicine in this population.

\section{CONCLUSION}

N-3 PUFAs has a crucial role in neurodevelopment, thus adequate supplementation for those who are deficient may help enhance the effects of the current standard treatments. It is to be kept in mind that any addition of the n-3 PUFAs supplementation should always be consulted initially with the child's primary psychiatrists, and if the children are already responding well with the current medication, the medication should not be discontinued, but rather considered to have n-3 PUFAs as an option for augmentation. In addition, if children are more prone to have symptoms such as dry and scaly skin, eczema, and dry eyes, it may indicate that they have a deficiency in EFAs such as n-3 PUFAs. Moreover, routine 6-12 months follow up on the biochemistry and lipid profiles of children using n-3 PUFAs is recommended, and if clinicians are not familiar with the high-quality n-3 PUFAs in the market, they should consider RxOM3FAs. Again, the recommendation is based on the current published studies available, more studies are encouraged to further investigate the role the $n-3$ PUFAs in these pediatric disorders and formulate a more refined guideline in the future in the aim of personalized medication with n-3 PUFAs in ADHD, ASD and MDD.

\section{Acknowledgments}

The authors of this work were supported by the following grants: MOST 106-2314-B-039-027-MY3, 108-2320B-039-048, 108-2813-C-039-133-B and 108-2314-B-039016 from the Ministry of Science and Technology, Taiwan; NHRI-EX108-10528NI from the National Health Research Institutes, Taiwan; MYRG2018-00242-ICMS from University of Macau, China; CMRC-CMA-3 from Higher Education Sprout Project by the Ministry of Education (MOE), Taiwan; CMU108-SR-106 from the China Medical University,
Taichung, Taiwan; and CMU104-S-16-01, CMU103-BC-4-1, CRS-108-048, DMR-108-216, DMR-109-102, DMR-109244, DMR-HHC-109-11 and DMR-HCC-109-12 from the China Medical University Hospital, Taichung, Taiwan.

\section{Conflicts of Interest}

No potential conflict of interest relevant to this article was reported.

\section{Author Contributions}

Conceptualization: Jane Pei-Chen Chang and Kuan-Pin Su. Funding: Kuan-Pin Su. Supervision: Kuan-Pin Su. Writing - original draft: Jane Pei-Chen Chang and Kuan-Pin Su. Writing - review \& editing: Kuan-Pin Su.

\section{ORCID}

Jane Pei-Chen Chang

https://orcid.org/0000-0001-5582-0928

Kuan-Pin Su https://orcid.org/0000-0002-4501-2502

\section{REFERENCES}

1. Das UN. Essential fatty acids: biochemistry, physiology and pathology. Biotechnol J 2006;1:420-439.

2. Connor WE. Importance of $n-3$ fatty acids in health and disease. Am J Clin Nutr 2000;71(1 Suppl):171S-175S.

3. Torpy JM, Lynm C, Glass RM. Eating fish: health benefits and risks. JAMA 2006:296:1926.

4. Hibbeln JR, Davis JM, Steer C, Emmett P, Rogers I, Williams $\mathrm{C}$, et al. Maternal seafood consumption in pregnancy and neurodevelopmental outcomes in childhood (ALSPAC study): an observational cohort study. Lancet 2007;369: 578-585.

5. Su KP, Huang SY, Chiu TH, Huang KC, Huang CL, Chang $\mathrm{HC}$, et al. Omega-3 fatty acids for major depressive disorder during pregnancy: results from a randomized, double-blind, placebo-controlled trial. J Clin Psychiatry 2008;69:644-651.

6. Su KP, Lai HC, Yang HT, Su WP, Peng CY, Chang JP, et al. Omega-3 fatty acids in the prevention of interferon-alphainduced depression: results from a randomized, controlled trial. Biol Psychiatry 2014;76:559-566.

7. Chang JP, Su KP, Mondelli V, Pariante CM. Omega-3 polyunsaturated fatty acids in youths with attention deficit hyperactivity disorder: a systematic review and meta-analysis of clinical trials and biological studies. Neuropsychopharmacology 2018:43:534-545.

8. Chiu CC, Su KP, Cheng TC, Liu HC, Chang CJ, Dewey ME, et al. The effects of omega-3 fatty acids monotherapy in Alzheimer's disease and mild cognitive impairment: a preliminary randomized double-blind placebo-controlled study. Prog Neuropsychopharmacol Biol Psychiatry 2008;32. 
1538-1544.

9. Chalon S. Omega-3 fatty acids and monoamine neurotransmission. Prostaglandins Leukot Essent Fatty Acids 2006;75: 259-269.

10. Su KP, Huang SY, Chiu CC, Shen WW. Omega-3 fatty acids in major depressive disorder. A preliminary double-blind, placebo-controlled trial. Eur Neuropsychopharmacol 2003; 13:267-271.

11. Lin PY, Su KP. A meta-analytic review of double-blind, placebo-controlled trials of antidepressant efficacy of omega-3 fatty acids. J Clin Psychiatry 2007;68:1056-1061.

12. Chang JP, Su KP, Mondelli V, Satyanarayanan SK, Yang HT, Chiang YJ, et al. High-dose eicosapentaenoic acid (EPA) improves attention and vigilance in children and adolescents with attention deficit hyperactivity disorder (ADHD) and low endogenous EPA levels. Transl Psychiatry 2019;9:303.

13. Cheng YS, Tseng PT, Chen YW, Stubbs B, Yang WC, Chen TY, et al. Supplementation of omega 3 fatty acids may improve hyperactivity, lethargy, and stereotypy in children with autism spectrum disorders: a meta-analysis of randomized controlled trials. Neuropsychiatr Dis Treat 2017;13. 2531-2543.

14. Chang JP. More fish-happier mom, smarter child? Brain Behav Immun 2018;73:157-158.

15. Labrousse VF, Leyrolle Q, Amadieu C, Aubert A, Sere A, Coutureau E, et al. Dietary omega-3 deficiency exacerbates inflammation and reveals spatial memory deficits in mice exposed to lipopolysaccharide during gestation. Brain Behav Immun 2018;73:427-440.

16. Lauritzen L, Brambilla P, Mazzocchi A, Harsløf LB, Ciappolino $\mathrm{V}$, Agostoni C. DHA effects in brain development and function. Nutrients 2016;8:6.

17. Agostoni C, Mazzocchi A, Leone L, Ciappolino V, Delvecchio G, Altamura CA, et al. The first model of keeping energy balance and optimal psycho affective development: breastfed infants. J Affect Disord 2017;224:10-15.

18. Innis SM. Omega-3 Fatty acids and neural development to 2 years of age: do we know enough for dietary recommendations? J Pediatr Gastroenterol Nutr 2009;48 Suppl 1:S16-S24.

19. Carver JD, Benford VJ, Han B, Cantor AB. The relationship between age and the fatty acid composition of cerebral cortex and erythrocytes in human subjects. Brain Res Bull 2001;56:79-85.

20. Browning LM, Walker CG, Mander AP, West AL, Madden J, Gambell JM, et al. Incorporation of eicosapentaenoic and docosahexaenoic acids into lipid pools when given as supplements providing doses equivalent to typical intakes of oily fish. Am J Clin Nutr 2012;96:748-758.

21. Chang JP, Su KP. The lipid raft hypothesis: the relation among omega-3 fatty acids, depression and cardiovascular diseases. Taiwanese J Psychiatry 2010;24:168-180.

22. Chang JP, Chang SS, Yang HT, Palani M, Chen CP, Su KP.
Polyunsaturated fatty acids (PUFAs) levels in patients with cardiovascular diseases (CVDs) with and without depression. Brain Behav Immun 2015;44:28-31.

23. Su KP. Biological mechanism of antidepressant effect of omega-3 fatty acids: how does fish oil act as a 'mind-body interface'? Neurosignals 2009;17:144-152.

24. Mazahery H, Stonehouse W, Delshad M, Kruger MC, Conlon CA, Beck KL, et al. Relationship between long chain $n-3$ polyunsaturated fatty acids and autism spectrum disorder: systematic review and meta-analysis of case-control and randomised controlled trials. Nutrients 2017;9:155.

25. SalLam M, Motaleb F, Ahmed M, Mahmoud A. Anti-inflammatory effect of omega-3 polyunsaturated fatty acids in children with bronchial asthma; relation to nuclear factor-kappa B (NF- $\kappa$ B) and inflammatory cytokines IL-12 and IL-13. Egypt J Biochem Mol Biol 2010. doi: 10.4314/ejbmb. v28i2.60793.

26. Zhang R, He GZ, Wang YK, Zhou KG, Ma EL. Omega-3 po/yunsaturated fatty acids inhibit the increase in cytokines and chemotactic factors induced in vitro by lymph fluid from an intestinal ischemia-reperfusion injury model. Nutrition 2015;31:508-514.

27. Farjadian S, Moghtaderi M, Kalani M, Gholami T, Hosseini Teshnizi S. Effects of omega-3 fatty acids on serum levels of T-helper cytokines in children with asthma. Cytokine 2016; 85:61-66.

28. Zhao Y, Joshi-Barve S, Barve S, Chen LH. Eicosapentaenoic acid prevents $L P S$-induced TNF-alpha expression by preventing NF-kappaB activation. J Am Coll Nutr 2004;23:71-78.

29. Farooqui AA, Horrocks LA. Phospholipase $A_{2}$-generated lipid mediators in the brain: the good, the bad, and the ugly. Neuroscientist 2006;12:245-260.

30. Rhee SH, Pothoulakis C, Mayer EA. Principles and clinical implications of the brain-gut-enteric microbiota axis. Nat Rev Gastroenterol Hepatol 2009;6:306-314.

31. Ganesh BP, Klopfleisch R, Loh G, Blaut M. Commensal Akkermansia muciniphila exacerbates gut inflammation in Salmonella Typhimurium-infected gnotobiotic mice. PLoS One 2013;8:e74963.

32. Frank DN, St Amand AL, Feldman RA, Boedeker EC, Harpaz $\mathrm{N}$, Pace NR. Molecular-phylogenetic characterization of microbial community imbalances in human inflammatory bowel diseases. Proc Natl Acad Sci U S A 2007; 104:1378013785.

33. Watson H, Mitra S, Croden FC, Taylor M, Wood HM, Perry $\mathrm{SL}$, et al. A randomised trial of the effect of omega-3 polyunsaturated fatty acid supplements on the human intestinal microbiota. Gut 2018;67:1974-1983.

34. Biederman J, Faraone SV. Attention-deficit hyperactivity disorder. Lancet 2005;366:237-248.

35. Biederman J, Newcorn J, Sprich S. Comorbidity of attention deficit hyperactivity disorder with conduct, depressive, anxiety, and other disorders. Am J Psychiatry 1991;148:564- 
577.

36. Biederman J, Faraone SV, Keenan K, Tsuang MT. Evidence of familial association between attention deficit disorder and major affective disorders. Arch Gen Psychiatry 1991;48: 633-642.

37. Wilens TE, Biederman J. A/cohol, drugs, and attention-deficit/ hyperactivity disorder: a model for the study of addictions in youth. J Psychopharmacol 2006;20:580-588.

38. Volkow ND, Swanson JM. Clinical practice: adult attention deficit-hyperactivity disorder. N Engl J Med 2013;369:19351944.

39. Childress AC, Sallee FR. Attention-deficit/hyperactivity disorder with inadequate response to stimulants: approaches to management. CNS Drugs 2014;28:121-129.

40. Chang JP, Jingling L, Huang YT, Lu YJ, Su KP. Delay aversion, temporal processing, and $n-3$ fatty acids intake in children with attention-deficit/hyperactivity disorder (ADHD). Clin Psychol Sci 2016;4:1094-1103.

41. Stevens LJ, Zentall SS, Deck JL, Abate ML, Watkins BA, Lipp SR, et al. Essential fatty acid metabolism in boys with attention-deficit hyperactivity disorder. Am J Clin Nutr 1995;62: 761-768.

42. Stevens L, Zhang W, Peck L, Kuczek T, Grevstad N, Mahon $\mathrm{A}$, et al. EFA supplementation in children with inattention, hyperactivity, and other disruptive behaviors. Lipids 2003; 38:1007-1021.

43. Colter AL, Cutler C, Meckling KA. Fatty acid status and behavioural symptoms of attention deficit hyperactivity disorder in adolescents: a case-control study. Nutr J 2008;7:8.

44. Brookes KJ, Chen W, Xu X, Taylor E, Asherson P. Association of fatty acid desaturase genes with attention-deficit/hyperactivity disorder. Biol Psychiatry 2006;60:1053-1061.

45. Cooper RE, Tye C, Kuntsi J, Vassos E, Asherson P. Omega-3 polyunsaturated fatty acid supplementation and cognition: a systematic review and meta-analysis. J Psychopharmacol 2015;29:753-763.

46. Gillies D, Sinn JK, Lad SS, Leach MJ, Ross MJ. Polyunsaturated fatty acids (PUFA) for attention deficit hyperactivity disorder $(A D H D)$ in children and adolescents. Cochrane Database Syst Rev 2012;2012:CD007986.

47. Hawkey E, Nigg JT. Omega-3 fatty acid and ADHD: blood level analysis and meta-analytic extension of supplementation trials. Clin Psychol Rev 2014;34:496-505.

48. Puri BK, Martins JG. Which polyunsaturated fatty acids are active in children with attention-deficit hyperactivity disorder receiving PUFA supplementation? A fatty acid validated meta-regression analysis of randomized controlled trials. Prostaglandins Leukot Essent Fatty Acids 2014;90: 179-189.

49. Sonuga-Barke EJ, Brandeis D, Cortese S, Daley D, Ferrin M, Holtmann M, et al. Nonpharmacological interventions for ADHD: systematic review and meta-analyses of randomized controlled trials of dietary and psychological treat- ments. Am J Psychiatry 2013;170:275-289.

50. Bloch $\mathrm{MH}$, Qawasmi A. Omega-3 fatty acid supplementation for the treatment of children with attention-deficit/hyperactivity disorder symptomatology: systematic review and meta-analysis. J Am Acad Child Adolesc Psychiatry 2011;50:991-1000.

51. Manor I, Magen A, Keidar D, Rosen S, Tasker H, Cohen T, et al. The effect of phosphatidylserine containing Omega3 fatty-acids on attention-deficit hyperactivity disorder symptoms in children: a double-blind placebo-controlled trial, followed by an open-label extension. Eur Psychiatry 2012; 27:335-342.

52. Perera H, Jeewandara KC, Seneviratne S, Guruge C. Combined $\omega 3$ and $\omega 6$ supplementation in children with attention-deficit hyperactivity disorder (ADHD) refractory to methylphenidate treatment: a double-blind, placebo-controlled study. J Child Neurol 2012;27:747-753.

53. Richardson AJ, Puri BK. A randomized double-blind, placebo-controlled study of the effects of supplementation with highly unsaturated fatty acids on ADHD-related symptoms in children with specific learning difficulties. Prog Neuropsychopharmacol Biol Psychiatry 2002;26:233-239.

54. Sinn N, Bryan J, Wilson C. Cognitive effects of polyunsaturated fatty acids in children with attention deficit hyperactivity disorder symptoms: a randomised controlled trial. Prostaglandins Leukot Essent Fatty Acids 2008;78:311-326.

55. Vaisman N, Kaysar N, Zaruk-Adasha Y, Pelled D, Brichon G, Zwingelstein G, et al. Correlation between changes in blood fatty acid composition and visual sustained attention performance in children with inattention: effect of dietary n-3 fatty acids containing phospholipids. Am J Clin Nutr 2008; 87:1170-1180.

56. Voigt RG, Llorente AM, Jensen CL, Fraley JK, Berretta MC, Heird WC. A randomized, double-blind, placebo-controlled trial of docosahexaenoic acid supplementation in children with attention-deficit/hyperactivity disorder. J Pediatr 2001; 139:189-196.

57. Widenhorn-Müller K, Schwanda S, Scholz E, Spitzer M, Bode $\mathrm{H}$. Effect of supplementation with long-chain $\omega$-3 polyunsaturated fatty acids on behavior and cognition in children with attention deficit/hyperactivity disorder (ADHD): a randomized placebo-controlled intervention trial. Prostaglandins Leukot Essent Fatty Acids 2014;91:49-60.

58. American Psychiatric Association. Diagnostic and statistical manual of mental disorders: DSM-5. 5th ed. Arlington:American Psychiatric Association;2013.

59. Marchezan J, Winkler Dos Santos EGA, Deckmann I, Riesgo RDS. Immunological dysfunction in autism spectrum disorder: a potential target for therapy. Neuroimmunomodulation 2018;25:300-319.

60. Rossignol DA, Frye RE. Evidence linking oxidative stress, mitochondrial dysfunction, and inflammation in the brain of individuals with autism. Front Physiol 2014;5:150. 
61. Napoli E, Wong S, Hertz-Picciotto I, Giulivi C. Deficits in bioenergetics and impaired immune response in granulocytes from children with autism. Pediatrics 2014;133:e1405-e1410.

62. El-Ansary A, Al-Ayadhi L. Lipid mediators in plasma of autism spectrum disorders. Lipids Health Dis 2012;11:160.

63. Adams JB, Baral M, Geis E, Mitchell J, Ingram J, Hensley A, et al. The severity of autism is associated with toxic metal body burden and red blood cell glutathione levels. J Toxicol 2009;2009:532640.

64. Rojas DC, Peterson E, Winterrowd E, Reite ML, Rogers SJ, Tregellas JR. Regional gray matter volumetric changes in autism associated with social and repetitive behavior symptoms. BMC Psychiatry 2006;6:56.

65. Pryweller JR, Schauder KB, Anderson AW, Heacock JL, Foss-Feig JH, Newsom CR, et al. White matter correlates of sensory processing in autism spectrum disorders. Neuroimage Clin 2014;6:379-387.

66. Bryn V, Halvorsen B, Ueland T, Isaksen J, Kolkova K, Ravn K, et al. Brain derived neurotrophic factor (BDNF) and autism spectrum disorders (ASD) in childhood. Eur J Paediatr Neurol 2015;19:411-414.

67. Cao D, Xue R, Xu J, Liu Z. Effects of docosahexaenoic acid on the survival and neurite outgrowth of rat cortical neurons in primary cultures. J Nutr Biochem 2005;16:538-546.

68. Robson LG, Dyall S, Sidloff D, Michael-Titus AT. Omega-3 polyunsaturated fatty acids increase the neurite outgrowth of rat sensory neurones throughout development and in aged animals. Neurobiol Aging 2010;31:678-687.

69. Calderon F, Kim HY. Docosahexaenoic acid promotes neurite growth in hippocampal neurons. J Neurochem 2004;90: 979-988.

70. Wu A, Ying Z, Gomez-Pinilla F. Dietary omega-3 fatty acids normalize BDNF levels, reduce oxidative damage, and counteract learning disability after traumatic brain injury in rats. J Neurotrauma 2004;21:1457-1467.

71. Brigandi SA, Shao H, Qian SY, Shen Y, Wu BL, Kang JX. Autistic children exhibit decreased levels of essential Fatty acids in red blood cells. Int J Mol Sci 2015;16:10061-10076.

72. Abdelmagid SA, Clarke SE, Roke K, Nielsen DE, Badawi A, El-Sohemy $\mathrm{A}$, et al. Ethnicity, sex, FADS genetic variation, and hormonal contraceptive use influence delta-5- and delta-6-desaturase indices and plasma docosahexaenoic acid concentration in young Canadian adults: a cross-sectional study. Nutr Metab (Lond) 2015;12:14.

73. Chouinard-Watkins R, Plourde M. Fatty acid metabolism in carriers of apolipoprotein E epsilon 4 allele: is it contributing to higher risk of cognitive decline and coronary heart disease? Nutrients 2014;6:4452-4471.

74. Shimamoto C, Ohnishi T, Maekawa M, Watanabe A, Ohba $\mathrm{H}$, Arai $\mathrm{R}$, et al. Functional characterization of $F A B P 3,5$ and 7 gene variants identified in schizophrenia and autism spectrum disorder and mouse behavioral studies. Hum Mol Genet 2014;23:6495-6511.
75. Al-Farsi YM, Waly MI, Deth RC, Al-Sharbati MM, Al-Shafaee $\mathrm{M}, \mathrm{Al}-\mathrm{Farsi} \mathrm{O}$, et al. Impact of nutrition on serum levels of docosahexaenoic acid among Omani children with autism. Nutrition 2013;29:1142-1146.

76. Ghezzo A, Visconti P, Abruzzo PM, Bolotta A, Ferreri C, Gobbi $\mathrm{G}$, et al. Oxidative stress and erythrocyte membrane alterations in children with autism: correlation with clinical features. PLoS One 2013;8:e66418.

77. Meiri G, Bichovsky Y, Belmaker RH. Omega 3 fatty acid treatment in autism. J Child Adolesc Psychopharmacol 2009; 19:449-451.

78. Ooi YP, Weng SJ, Jang LY, Low L, Seah J, Teo S, et al. Omega-3 fatty acids in the management of autism spectrum disorders: findings from an open-label pilot study in Singapore. Eur J Clin Nutr 2015;69:969-971.

79. Amminger GP, Berger GE, Schäfer MR, Klier C, Friedrich $\mathrm{MH}$, Feucht M. Omega-3 fatty acids supplementation in children with autism: a double-blind randomized, placebo-controlled pilot study. Biol Psychiatry 2007;61:551-553.

80. Mankad D, Dupuis A, Smile S, Roberts W, Brian J, Lui T, et al. A randomized, placebo controlled trial of omega-3 fatty acids in the treatment of young children with autism. Mol Autism 2015;6:18.

81. Katan MB, Deslypere JP, van Birgelen AP, Penders M, Zegwaard M. Kinetics of the incorporation of dietary fatty acids into serum cholesteryl esters, erythrocyte membranes, and adipose tissue: an 18-month controlled study. J Lipid Res 1997;38:2012-2022.

82. Stonehouse W. Does consumption of LC omega-3 PUFA enhance cognitive performance in healthy school-aged children and throughout adulthood? Evidence from clinical trials. Nutrients 2014;6:2730-2758.

83. Raine A, Portnoy J, Liu J, Mahoomed T, Hibbeln JR. Reduction in behavior problems with omega-3 supplementation in children aged 8-16 years: a randomized, double-blind, placebo-controlled, stratified, parallel-group trial. J Child Psychol Psychiatry 2015;56:509-520.

84. Horvath A, Łukasik J, Szajewska H. $\omega-3$ fatty acid supplementation does not affect autism spectrum disorder in children: a systematic review and meta-analysis. J Nutr 2017; 147:367-376.

85. March JS, Silva S, Petrycki S, Curry J, Wells K, Fairbank J, et al. The Treatment for Adolescents with Depression Study (TADS): long-term effectiveness and safety outcomes. Arch Gen Psychiatry 2007;64:1132-1143.

86. Chang JP, Lin CY, Lin PY, Shih YH, Chiu TH, Ho M, et al. Polyunsaturated fatty acids and inflammatory markers in major depressive episodes during pregnancy. Prog Neuropsychopharmacol Biol Psychiatry 2018;80(Pt C):273-278.

87. Hibbeln JR, Nieminen LR, Blasbalg TL, Riggs JA, Lands WE. Healthy intakes of $n-3$ and $n-6$ fatty acids: estimations considering worldwide diversity. Am J Clin Nutr 2006;83(6 Suppl):1483S-1493S. 
88. Chang JP, Chang SS, Yang HT, Chen HT, Chien YC, Yang B, et al. Omega-3 polyunsaturated fatty acids in cardiovascular diseases comorbid major depressive disorder- results from a randomized controlled trial. Brain Behav Immun 2020;85: 14-20.

89. Peet M, Horrobin DF. A dose-ranging study of the effects of ethyl-eicosapentaenoate in patients with ongoing depression despite apparently adequate treatment with standard drugs. Arch Gen Psychiatry 2002;59:913-919.

90. Stoll AL, Severus WE, Freeman MP, Rueter S, Zboyan HA, Diamond $\mathrm{E}$, et al. Omega 3 fatty acids in bipolar disorder: a preliminary double-blind, placebo-controlled trial. Arch Gen Psychiatry 1999;56:407-412.

91. Chiu CC, Huang SY, Chen CC, Su KP. Omega-3 fatty acids are more beneficial in the depressive phase than in the manic phase in patients with bipolar I disorder. J Clin Psychiatry 2005; 66:1613-1614.

92. Su KP, Shen WW, Huang SY. Are omega3 fatty acids beneficial in depression but not mania? Arch Gen Psychiatry 2000;57:716-717.

93. Guida F, Turco F, lannotta M, De Gregorio D, Palumbo I, Sarnelli G, et al. Antibiotic-induced microbiota perturbation causes gut endocannabinoidome changes, hippocampal neuroglial reorganization and depression in mice. Brain Behav Immun 2018;67:230-245.

94. Kelly JR, Borre Y, O’ Brien C, Patterson E, El Aidy S, Deane J, et al. Transferring the blues: depression-associated gut microbiota induces neurobehavioural changes in the rat. J Psychiatr Res 2016;82:109-118.

95. Zheng P, Zeng B, Zhou C, Liu M, Fang Z, Xu X, et al. Gut microbiome remodeling induces depressive-like behaviors through a pathway mediated by the host's metabolism. Mol Psychiatry 2016;21:786-796.

96. van de Wouw M, Boehme M, Lyte JM, Wiley N, Strain C, O'Sullivan O, et al. Short-chain fatty acids: microbial metabolites that alleviate stress-induced brain-gut axis alterations. J Physiol 2018;596:4923-4944.

97. Jiang $\mathrm{H}$, Ling Z, Zhang Y, Mao H, Ma Z, Yin Y, et al. Altered fecal microbiota composition in patients with major depressive disorder. Brain Behav Immun 2015;48:186-194.

98. Tedelind S, Westberg F, Kjerrulf M, Vidal A. Anti-inflammatory properties of the short-chain fatty acids acetate and propionate: a study with relevance to inflammatory bowel disease. World J Gastroenterol 2007;13:2826-2832.

99. Bourassa MW, Alim I, Bultman SJ, Ratan RR. Butyrate, neuroepigenetics and the gut microbiome: can a high fiber diet improve brain health? Neurosci Lett 2016;625:56-63.

100. Trompette A, Gollwitzer ES, Yadava K, Sichelstiel AK, Sprenger N, Ngom-Bru C, et al. Gut microbiota metabolism of dietary fiber influences allergic airway disease and hematopoiesis. Nat Med 2014;20:159-166.

101. Sgoifo A, Carnevali L, Alfonso Mde L, Amore M. Autonomic dysfunction and heart rate variability in depression. Stress
2015; 18:343-352.

102. Paniccia M, Verweel L, Thomas S, Taha T, Keightley M, Wilson $\mathrm{KE}$, et al. Heart rate variability in healthy non-concussed youth athletes: exploring the effect of age, sex, and concussion-like symptoms. Front Neurol 2018;8:753.

103. Vloet TD, Jans T, Frey A, Häußler M, Vloet A, Geissler J, et al. Mean heart rate and parameters of heart rate variability in depressive children and the effects of antidepressant medication. Z Kinder Jugendpsychiatr Psychother 2019;47: 253-260.

104. Hibbeln JR, Ferguson TA, Blasbalg TL. Omega-3 fatty acid deficiencies in neurodevelopment, aggression and autonomic dysregulation: opportunities for intervention. Int Rev Psychiatry 2006;18:107-118.

105. Christensen JH. Omega-3 polyunsaturated fatty acids and heart rate variability. Front Physiol 2011;2:84.

106. Lauritzen L, Christensen JH, Damsgaard CT, Michaelsen KF. The effect of fish oil supplementation on heart rate in healthy Danish infants. Pediatr Res 2008;64:610-614.

107. Pivik RT, Dykman RA, Jing H, Gilchrist JM, Badger TM. Early infant diet and the omega 3 fatty acid DHA: effects on resting cardiovascular activity and behavioral development during the first half-year of life. Dev Neuropsychol 2009;34:139-158.

108. Chang JP, Guu TW, Chen YC, Gałecki P, Walczewska A, Su KP. Banl polymorphism of cytosolic phospholipase A2 gene and somatic symptoms in medication-free acute depressed patients. Prostaglandins Leukot Essent Fatty Acids 2018; 136:111-115.

109. Su KP, Huang SY, Peng CY, Lai HC, Huang CL, Chen YC, et al. Phospholipase A2 and cyclooxygenase 2 genes influence the risk of interferon-alpha-induced depression by regulating polyunsaturated fatty acids levels. Biol Psychiatry 2010; 67:550-557.

110. Guu TW, Mischoulon D, Sarris J, Hibbeln J, McNamara RK, Hamazaki K, et al. International Society for Nutritional Psychiatry Research practice guidelines for omega-3 fatty acids in the treatment of major depressive disorder. Psychother Psychosom 2019;88:263-273.

111. Nishi D, Su KP, Usuda K, Chang JPC, Chiang YJ, Chen HT, et al. The efficacy of omega-3 fatty acids for depressive symptoms among pregnant women in Japan and Taiwan: a randomized, double-blind, placebo-controlled trial (SYNCHRO; NCT01948596). Psychother Psychosom 2019; 88:122-124.

112. Nishi D, Su KP, Usuda K, Chang JP, Hamazaki K, Ishima T, et al. Plasma estradiol levels and antidepressant effects of omega-3 fatty acids in pregnant women. Brain Behav Immun 2020;85:29-34.

113. Nishi D, Su KP, Usuda K, Chiang YJ, Guu TW, Hamazaki K, et al. Omega-3 fatty acid supplementation for expectant mothers with depressive symptoms in Japan and Taiwan: An open-label trial. Psychiatry Clin Neurosci 2016;70:253-254.

114. McNamara RK, Strimpfel J, Jandacek R, Rider T, Tso P, 
Welge JA, et al. Detection and treatment of long-chain omega-3 fatty acid deficiency in adolescents with SSRI-resistant major depressive disorder. PharmaNutrition 2014;2:38-46.

115. Gabbay V, Freed RD, Alonso CM, Senger S, Stadterman J, Davison BA, et al. A double-blind placebo-controlled trial of omega-3 fatty acids as a monotherapy for adolescent depression. J Clin Psychiatry 2018;79:17m11596.

116. Nemets H, Nemets B, Apter A, Bracha Z, Belmaker RH. Omega-3 treatment of childhood depression: a controlled, double-blind pilot study. Am J Psychiatry 2006;163:10981100.

117. Trebatická J, Hradečná Z, Böhmer F, Vaváková $M$, Waczulíková I, Garaiova I, et al. Emulsified omega-3 fatty-acids modulate the symptoms of depressive disorder in children and adolescents: a pilot study. Child Adolesc Psychiatry Ment Health 2017;11:30.

118. Harris WS. Expert opinion: omega-3 fatty acids and bleeding-cause for concern? Am J Cardiol 2007;99:44C-46C.

119. Matsuo N. Studies on the toxicity of fish oil. V. Toxicity of oxidized commercial cod-liver oil. Tokushima J Exp Med 1961;8:96-100

120. Palozza P, Sgarlata E, Luberto C, Piccioni E, Anti M, Marra G, et al. N-3 fatty acids induce oxidative modifications in human erythrocytes depending on dose and duration of dietary supplementation. Am J Clin Nutr 1996;64:297-304.

121. Grundt H, Nilsen DW, Mansoor MA, Nordøy A. Increased lipid peroxidation during long-term intervention with high doses of n-3 fatty acids (PUFAs) following an acute myocardial infarction. Eur J Clin Nutr 2003;57:793-800.

122. Halvorsen B, Almendingen K, Nenseter MS, Pedersen JI, Christiansen EN. Effects of partially hydrogenated fish oil, partially hydrogenated soybean oil and butter on the susceptibility of low density lipoprotein to oxidative modification in men. Eur J Clin Nutr 1996;50:364-370.

123. Calviello G, Palozza P, Franceschelli P, Bartoli GM. Low-dose eicosapentaenoic or docosahexaenoic acid administration modifies fatty acid composition and does not affect susceptibility to oxidative stress in rat erythrocytes and tissues. Lipids 1997;32:1075-1083.

124. Turley E, Wallace JM, Gilmore WS, Strain JJ. Fish oil supplementation with and without added vitamin E differentially modulates plasma antioxidant concentrations in healthy women. Lipids 1998;33:1163-1167.

125. Linseisen J, Hoffmann J, Lienhard S, Jauch KW, Wolfram G. Antioxidant status of surgical patients receiving TPN with an omega-3-fatty acid-containing lipid emulsion supplemented with alpha-tocopherol. Clin Nutr 2000;19:177-184.

126. Higdon JV, Du SH, Lee YS, Wu T, Wander RC. Supplementation of postmenopausal women with fish oil does not increase overall oxidation of $L D L$ ex vivo compared to dietary oils rich in oleate and linoleate. J Lipid Res 2001;42:407-418.

127. Higgins S, Carroll YL, McCarthy SN, Corridan BM, Roche $\mathrm{HM}$, Wallace JM, et al. Susceptibility of $L D L$ to oxidative modification in healthy volunteers supplemented with low doses of n-3 polyunsaturated fatty acids. Br J Nutr 2001;85: 23-31.

128. Rhodes LE, Shahbakhti H, Azurdia RM, Moison RM, Steenwinkel MJ, Homburg MI, et al. Effect of eicosapentaenoic acid, an omega-3 polyunsaturated fatty acid, on UVRrelated cancer risk in humans. An assessment of early genotoxic markers. Carcinogenesis 2003;24:919-925.

129. Wheaton DH, Hoffman DR, Locke KG, Watkins RB, Birch DG. Biological safety assessment of docosahexaenoic acid supplementation in a randomized clinical trial for X-linked retinitis pigmentosa. Arch Ophthalmol 2003;121:1269-1278.

130. Tholstrup T, Hellgren LI, Petersen M, Basu S, Straarup EM, Schnohr $\mathrm{P}$, et al. A solid dietary fat containing fish oil redistributes lipoprotein subclasses without increasing oxidative stress in men. J Nutr 2004;134:1051-1057.

131. Mohan IK, Das UN. Oxidant stress, anti-oxidants and essential fatty acids in systemic lupus erythematosus. Prostaglandins Leukot Essent Fatty Acids 1997;56:193-198.

132. Wander RC, Du SH, Thomas DR. Influence of long-chain polyunsaturated fatty acids on oxidation of low density lipoprotein. Prostaglandins Leukot Essent Fatty Acids 1998; 59:143-151.

133. Véricel E, Calzada C, Chapuy P, Lagarde M. The influence of low intake of $n-3$ fatty acids on platelets in elderly people. Atherosclerosis 1999;147:187-192.

134. Ramírez-Tortosa MC, Suárez A, Gómez MC, Mir A, Ros E, Mataix J, et al. Effect of extra-virgin olive oil and fish-oil supplementation on plasma lipids and susceptibility of lowdensity lipoprotein to oxidative alteration in free-living Spanish male patients with peripheral vascular disease. Clin Nutr 1999;18:167-174.

135. Mori TA, Puddey IB, Burke V, Croft KD, Dunstan DW, Rivera $\mathrm{JH}$, et al. Effect of omega 3 fatty acids on oxidative stress in humans: GC-MS measurement of urinary F2-isoprostane excretion. Redox Rep 2000;5:45-46.

136. Yavin E, Glozman S, Green P. Docosahexaenoic acid accumulation in the prenatal brain: prooxidant and antioxidant features. JMol Neurosci 2001;16:229-235; discussion 279-284.

137. Jain S, Gaiha M, Bhattacharjee J, Anuradha S. Effects of low-dose omega-3 fatty acid substitution in type-2 diabetes mellitus with special reference to oxidative stress--a prospective preliminary study. J Assoc Physicians India 2002; 50:1028-1033.

138. Mori TA, Woodman RJ, Burke V, Puddey IB, Croft KD, Beilin LJ. Effect of eicosapentaenoic acid and docosahexaenoic acid on oxidative stress and inflammatory markers in treated-hypertensive type 2 diabetic subjects. Free Radic Biol Med 2003;35:772-781.

139. Barbosa DS, Cecchini R, El Kadri MZ, Rodríguez MA, Burini $\mathrm{RC}$, Dichi I. Decreased oxidative stress in patients with ulcerative colitis supplemented with fish oil omega-3 fatty acids. Nutrition 2003;19:837-842. 
140. Abel S, De Kock M, Smuts CM, de Villiers C, Swanevelder S, Gelderblom WC. Dietary modulation of fatty acid profiles and oxidative status of rat hepatocyte nodules: effect of different n-6/n-3 fatty acid ratios. Lipids 2004;39:963-976.

141. Parinyasiri U, Ong-Ajyooth L, Parichatikanond P, Ong-Ajyooth S, Liammongkolkul S, Kanyog S. Effect of fish oil on oxidative stress, lipid profile and renal function in IgA nephropathy. J Med Assoc Thai 2004;87:143-149.

142. Chang CH, Tseng PT, Chen NY, Lin PC, Lin PY, Chang JP, et al. Safety and tolerability of prescription omega-3 fatty acids: a systematic review and meta-analysis of randomized controlled trials. Prostaglandins Leukot Essent Fatty Acids 2018;129:1-12.

143. Siscovick DS, Barringer TA, Fretts AM, Wu JH, Lichtenstein $\mathrm{AH}$, Costello RB, et al. Omega-3 polyunsaturated fatty acid (fish oil) supplementation and the prevention of clinical cardiovascular disease: a science advisory from the American Heart Association. Circulation 2017;135:e867-e884.

144. Bradberry JC, Hilleman DE. Overview of omega-3 fatty acid therapies. P T 2013;38:681-691.

145. Rapaport MH, Nierenberg AA, Schettler PJ, Kinkead B, Cardoos A, Walker R, et al. Inflammation as a predictive biomarker for response to omega-3 fatty acids in major depressive disorder: a proof-of-concept study. Mol Psychiatry 2016;21:71-79.

146. Lin PY, Mischoulon D, Freeman MP, Matsuoka Y, Hibbeln J, Belmaker RH, et al. Are omega-3 fatty acids antidepressants or just mood-improving agents? The effect depends upon diagnosis, supplement preparation, and severity of depression. Mol Psychiatry 2012;17:1161-1163. 